\title{
The elaboration of environmental sensitivity indices (ESI) maps of the Marine Protected Area of Baia
}

\author{
F. Gugliermetti, F. Cumo \& A. Monaco \\ Department of "Fisica Tecnica" Rome University "La Sapienza", Italy
}

\begin{abstract}
Environmental sensitivity maps for hydrocarbon spills are a useful instrument for highlighting those stretches of coastline and waters that are most vulnerable to oil spills. With this in mind a method for evaluating environmental sensitivity indices has been drawn up. Different natural and anthropic factors that would be affected by a spill have been taken into account in terms of damage to the environment, landscape, cultural and historical heritage and the economy. The structural and physical characteristics that would in any way alter the probability of contact with hydrocarbons or the difficulty of clean up of a particular area have also been considered.

The aim of the study was to analyse the submerged archaeological park of Baia in order to draw up a map of the varying degrees of sensitivity to oil spills present in this protected marine area. The study offered the opportunity to validate the tested methods and obtain an overview of the sensitivity to hydrocarbon spills in an area where the situation is particularly complex due to the coexistence of important submerged Roman remains, protected marine species and intense human activity, particularly related to tourism. The data collected during the field trip and the sensitivity indices that were subsequently drawn up are a valuable database for the local community and the public administration for the application of the principles of Integrated Coastal Zone Management, as well as for the prevention of major environmental disasters from all too frequent hydrocarbon spill accidents.
\end{abstract}

Keywords: oil spills, environmental sensitivity indices map, hydrocarbon pollution, integrated coastal zone management. 


\section{Introduction}

Thanks in part to the incomparable beauty of its coasts and waters, the Mediterranean Sea stands as one of the most extraordinary and highest examples of human culture of all time. The many studies carried out on the Mediterranean, or Mare Nostrum as the Romans called it, have revealed that these waters are particularly abundant in endemism and support an extraordinarily high concentration of species in relation to their overall volume. These characteristics qualify the Mediterranean as one of the global biodiversity 'hotspots', as recognised by major international environment protection institutions such as the International Union for the Conservation of Nature (IUCN), the United Nations Environment Programme (UNEP) and the Convention on Biological Diversity (CBD) [1]. Due to its central position within the Mediterranean, Italy - which stretches from Lampedusa to the Gulf of Trieste - is emblematic of this vast land, marine and coastal biodiversity, particularly in terms of species and habitat (biotope) variety.

With roughly 300 million inhabitants along its shores, the Mediterranean Sea is currently also at high environmental risk, threatened by a number of factors including the introduction of alien species (that threaten local endemism), and the oil trade (with roughly 160 million tons of hydrocarbons transported through its waters every year). With the recent development of tourism (the entire area supports an influx of roughly 100 million tourists a year), this situation requires an ever greater attention to management and conservation with a view to preserving the many biological, natural and landscape resources that have always characterised the Mediterranean.

As well as offering an instrument for reducing pollution in coastal waters, the project is intended to provide protection for the Italian coastline, which is a common resource of considerable importance in terms of the natural, economic, social, historical and cultural phenomena in which it has played a leading role over thousands of years. It is therefore necessary to implement an integrated management and control of this area so that it can preserve or recover its environmental integrity within a framework of optimising the cost/benefit ratio and continually improving the quality of life of the human communities that live here.

The progressive increase in sea traffic since the 1960s has caused growing concern for one of the fundamental aspects of pollution prevention: avoiding spills of hydrocarbons into the sea, which is particularly damaging to waters that are closed and subjected to heavy traffic such as the Mediterranean [2].

When a sizeable oil spill takes place, low density hydrocarbons tend to spread out over the water surface, creating a thin layer that obstructs the sun's rays and consequently reduces photosynthesis. This reduces the water-air interface gas exchange, which has the immediate effect of reducing the quantity of oxygen present in the environment. The oil in fact blocks the passage of oxygen from the atmosphere into the sea water, also because the bacteria that break down hydrocarbons consume considerable quantities of molecular oxygen [3]. All organisms that inhabit the upper layers of the sea are damaged considerably 
given that photosynthesis is blocked and the development of phytoplankton - the essential root of the marine food chain - is therefore compromised [4]. Furthermore, after the more volatile components have evaporated, the toxic residue sinks and begins to interact with benthonic components in the depths, whose structure they alter and, once they reach the coastline, cause the death of the meso and supra-littoral biocenisis they enter into contact with [5]. No less relevant is the damage to birdlife and, more generally, to the macro fauna of marine and coastal areas that are particularly sensitive to oil spills in two ways: direct intoxication through direct swallowing of hydrocarbons, or from the gases emitted by the volatile components, and death from hypothermia due to the loss of the hydro-repellent quality of plumage that causes a lack of thermal insulation. Birdlife is in fact top of the list in terms of damage from past disasters (it has been estimated that 100-300,000 marine birds died following the Exxon Valdez disaster in Alaska in 1989).

As well as the damage to the environment, there would also be catastrophic damage to humans, largely due to the ascertained problems of bio-accumulation of cancerogenous toxic substances in edible fish. If the damage were to take place near fish farming or aquafarm structures or areas heavily frequented by tourists, the damage would be immeasurable. And last but not least, these analysis parameters should include the damage that would be incurred in the event of an oil spill taking place near coastlines with ruins of historical, archaeological or landscape value - potentially irreversible damage to structures of inestimable historical value.

With a view to minimising damage from oil spills, the environmental sensitivity maps therefore represent a concrete instrument for obtaining an overall view of vulnerability factors along coastal areas in the event of an accidental oil spill. The environmental sensitivity maps permit a clear comparison between two different coastal areas with regards to sensitivity to oil spills through numbers that sum up the various elements exposed to damage, be they biological, environmental, landscape or anthropic.

It is therefore possible to organise preventive action in order to provide priority conservation to coastal areas with particular biological (havens for one or more endangered species, the presence of reproductive areas, particular communities that need protection or the presence of birdlife) or anthropic scenarios (areas with a high tourism influx, with important coastal landscapes or with priceless historical or archaeological structures).

\section{Methods}

The mapping of environmental sensitivity indices for the protected marine area of Baia was obtained using three matrices (natural coastlines, water stretches and artificial features) that had been previously drawn up especially for calculating this kind of sensitivity within a Mediterranean context [6]. This protected area has a large number of submerged Roman period archaeological remains. On account of its pleasing landscape and the presence of thermal water springs the aristocracy of imperial Rome considered Baia a desirable holiday destination [7]. 
Over the centuries the bradisismic phenomena present in the entire area have gradually lowered the level of the entire coastline to such an extent that precious Roman remains such as statues, columns, roads and mosaics are now between six and twelve metres below sea level. The entire area is in fact intensely volcanic, as implied by the name itself which derives from the Greek " $\varphi \lambda \varepsilon \gamma \rho \alpha 10 \varsigma "$, meaning "blazing". The volcanic activity in this area has manifested itself chiefly as bradisism, the slow ascending or descending movement of the earth's crust due to the rising and cooling of magma beneath. Submerged villas such as the Villa dei Pisoni, along with the ancient port structures and Roman fisheries, have contributed towards making this area one of the most interesting submerged archaeological sites in Italy.

These elements of historical and archaeological value exist within a typically Mediterranean marine habitat, which abounds in marine phanerogams meadows (Posidonia oceanica and Cymodocea nodosa), as well as other species and habitats that have been listed as being of priority importance in the protocols of the Barcelona Convention and in the EU "Natura 2000" directive.

Up until a few decades ago meadows of Posidonia oceanica were common in the Gulf of Naples. Recent studies, however, show that there has been a sharp reduction of these meadows in the waters of the province of Naples. According to the most recent observations Posidonia oceanica is now confined to the waters around the islands of Ischia, Procida and Capri, as well as in the marine protected area of Baia [8]. The natural habitat of the seabed in this protected area is remarkable because of its great variety of microhabitats that generate an elevated degree of biodiversity. These microhabitats are the result of the interaction of a number of natural processes (bradisism, marine erosion, emissions from a secondary volcano) and of the unusual presence of submerged archaeological structures that constitute the only hard substrata for organisms that colonise bright and shade environments in a seabed that is otherwise sandy and muddy [9].

This inestimable environmental and archaeological heritage is in an area with special landscape features as well as port and tourism infrastructures [10].

Field work was carried out in this unique area of the Mediterranean with a view to gathering data concerning the coastal morphology and obtain valid results. We gathered all the data necessary for the compilation of the matrices used in calculating environmental sensitivity indices (ESI: Environmental Sensitivity Index) to oil spill risks in the submerged archaeological park of Baia.

A GPS (Garmin) instrument was used to provide the precise geographical coordinates of each particular information. In order to test the level of accuracy of the instrument, the error margin of the GPS was recorded before work begun by using known coordinates of points such as the summits delimiting the protected marine area.

Particular attention was devoted to recording in GPS all the points at which the type of coastline changed (beachy, rocky, etc.) or at which one of the calculation parameters for risk factor, such as impact value or damage index, varied within a single type of coast. Coastal sloping, the approximate granulometric composition of sediments and any additional environmental or 
anthropic value was also recorded. Where possible, the coastal mapping was carried out on foot, otherwise a small rubber dinghy was used to access more impervious areas. The coastal mapping was also useful for obtaining the necessary data for compiling the third matrix. Of each structure we recorded altitude, the kind of contact surface, use (commercial, services etc.) and additional value such as archaeological or landscape etc.

The marine data were gathered by underwater diving and reconnaissance by sea and their coordinates were annotated in the same way as those on land.

Information concerning water depth was obtained with the "Bluechart" nautical software, while information concerning archaeological remains obtained from the Soprintendenza per i Beni Archeologici di Napoli e Caserta completed and validated the underwater field work [11].

During this phase of proceedings the study area was photographed in detail, so that the information gathered could be accompanied by images of the places in question.

During the field survey we found that it was necessary to enlarge the area of analysis to include a number of areas adjacent to the marine protected area, in order to compare results from the protected area with areas outside.

A first look at the data confirmed our bibliographical references and revealed the presence of areas of considerable archaeological and naturalistic interest also in areas outside the underwater park of Baia. In particular we noticed important archaeological remains all along the coastline and beneath the water surface behind the castle of Baia, towards Capo Miseno, as well as a considerable presence of protected species such as Pinna nobilis, Posidonia oceanica and Cymodocea nodosa.

Following the analyses conducted in the field survey, all recorded information was transferred onto the "Arc Gis 9.1" software, thus providing a first classification of the areas of interest according to the different morphological, biological, historical and cultural values that made up the matrices.

Working with GIS offered an overall view of the various elements of the project, bringing together the information and geographical placing in a single picture.

All the data inserted into GIS was given a geographical reference with the WGS 84 coordinates system and gathered under different shapefiles: type of coast (beaches, rocky shores, cliffs, artificial coastal structures), depth (with the following values: from zero to two, from two to five, from five to ten and over ten metres), water stretches (fish farms, submerged archaeological remains, benthonic biocenosis and marine phanerogams meadows).

Two species of allochtonous algae of tropical origin were also found during the field trip: Caulerpa prolifera and Caulerpa racemosa.

These green varieties of algae were spotted in Italy for the first time in 1993 [12]. They are considered invasive and are spreading rapidly throughout the Mediterranean. Recent studies indicate that their spread causes a loss in the biodiversity of our waters, due largely to the fact that they substitute the Posidonia oceanica and Cymodocea nodosa meadows [13]. The underwater field work carried out in the marine protected area of Baia revealed a coexistence of 
meadows of phanerogams and allochtonous algae, with an increase of infesting algae at the expense of posidonia and cimodocea. A hydrocarbon spill would accelerate the demise of these algae and favour further colonisation from varieties such as Caulerpa, which are more resistant to environments with less light.

All the information gathered was inserted into shapefiles equipped with a table containing other information on the area in question (sloping, altitude, date in which the information was gathered, linear and surface dimension, etc).

These shapefiles were then used to create - still in GIS - environmental sensitivity maps of the protected marine area of Baia.

\section{Results}

The environmental sensitivity map sums up the output that emerged from the data gathered in the protected marine area and from the study of the matrices applied to these areas.

A colour corresponding to the ESI (from ESI I to IV) was assigned to each coastal and marine area of the park, so as to highlight the marine (figure 1) or coastal (figure 2 and figure 3 ) areas exposed to the greatest potential damage in the event of an oil spill.

The greater ESI values both for coast and water stretches appeared within zone A (integral preserve) and B (general preserve), in conformity with the criteria used to outline the borders of the protected marine area.

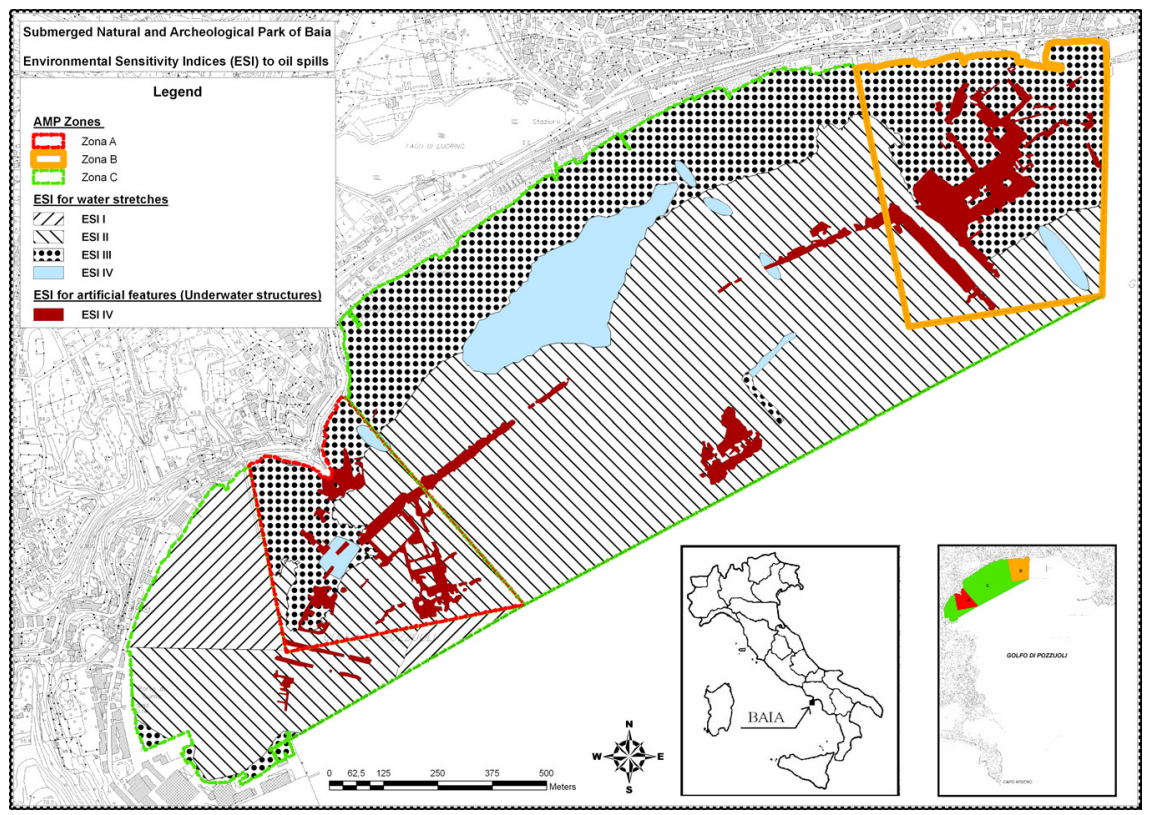

Figure 1: Environmental Sensitivity Indices (ESI) for water stretches in the Submerged Natural and Archaeological Park of Baia. 
The results confirmed the validity of the matrices that had been drawn up previously and which turned out to be suitable to a situation of such complexity, combining submerged Roman archaeological remains, protected marine species and tourist infrastructures along the coastline.

The matrix calculation for obtaining the ESI therefore proved itself to be versatile and easily applicable to the variety of contexts present along the Italian coastlines.

\section{Conclusions}

The environmental sensitivity indices obtained from the study of the different scenarios present in the areas that were examined have been used to create environmental sensitivity maps where lines and colours enable the viewer to identify those areas that are particularly vulnerable to an accidental spill.

This method offers a clear system for pinpointing landscape and cultural priorities, so that special protection can be afforded to areas that are most vulnerable to hydrocarbon spills.

The mapping work described above, carried out in the areas adjacent to the Submerged Natural and Archaeological Park of Baia, constitutes also reliable information for proposing a redefinition of the marine protected area boundaries.

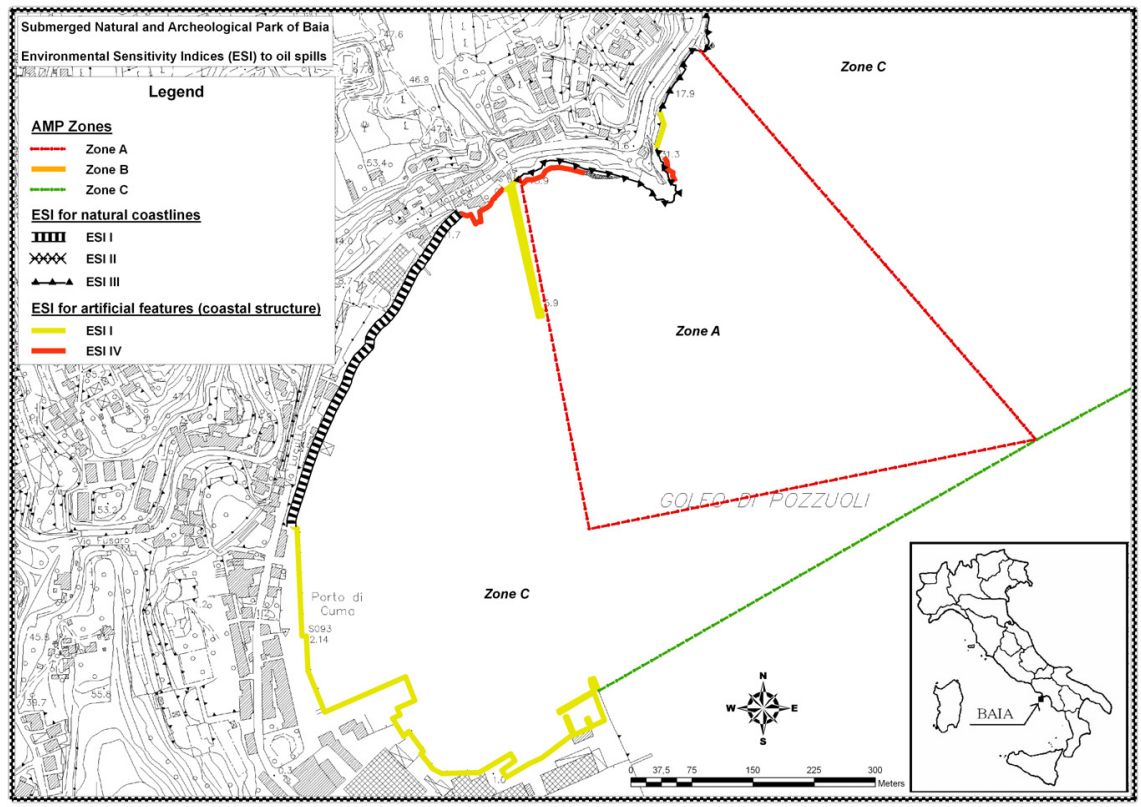

Figure 2: Environmental Sensitivity Indices (ESI) for natural and artificial coastlines in Zone A and part of Zone C of the Submerged Natural and Archaeological Park of Baia. 
An extension of the "C zone" (partial preserve) towards the south west would in fact bring more submerged and coastal remains of historical and archaeological value under protection, as well as reduce the impact of human activities on more sensitive areas of the submerged park (such as the "A zone", integral preserve zone). These buffer areas, which serve to attenuate destabilising effects and anthropic disturbance from outside the marine protected areas, are proven to be essential for the tutelage of the core area that they surround. They also act as a biotic connection between the benthonic biocenosis in the core area and external areas.

Lastly, the creation of a complex GIS (Geographic Information System) database comprises a precious quantity of information that can be used in a variety of ways by stakeholders for a broad range of integrated management purposes. They also contribute towards a greater knowledge of the biological, historical and functional aspects that characterise our coastlines and seas and make them so unique.

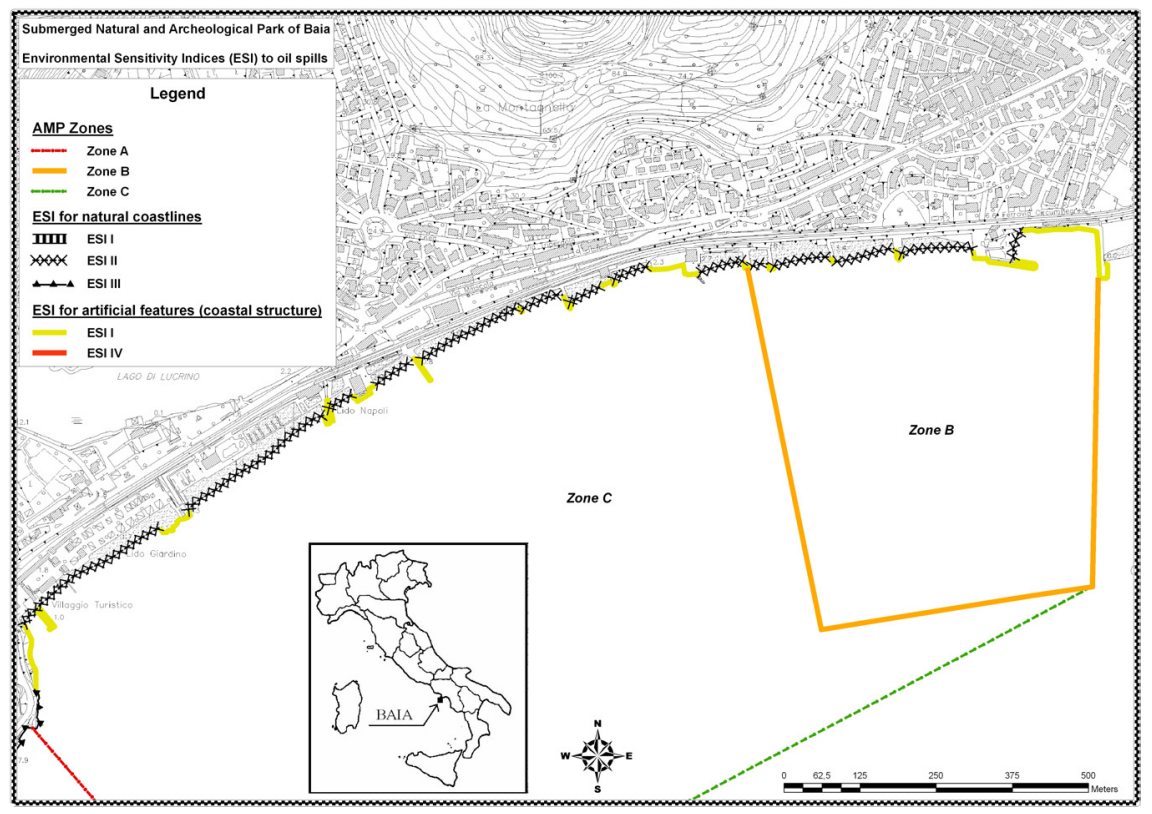

Figure 3: Environmental Sensitivity Indices (ESI) for natural and artificial coastlines in Zone B and part of Zone C of the Submerged Natural and Archaeological Park of Baia.

\section{References}

[1] Italian Ministry for the Environment, Land and Sea Protection. Mediterraneano. Ambienti, paesaggi, diversità. Téchne Editore. 
[2] Cinquepalmi F. Traffico petrolifero nel Mediterraneo: il quadro normativo e le politiche ambientali. in "Biodiversità marina e strategie di riduzione del rischio connesso al trasporto di Idrocarburi”, study day minutes, Rome, October 2005.

[3] Cognetti G., Cognetti G. Inquinamenti e protezione del mare. Calderini editore, 1992.

[4] Cinquepalmi F. Traffico Petrolifero: scenari di rischio ambientale. In Biodiversità Italiana, year I, issue 1, July/September, l'Aquila 2006.

[5] Della Croce N., Cattaneo Vietti R., Danovaro R. Ecologia e protezione dell'ambiente marino costiero. Utet Libreria, 2001.

[6] Gugliermetti F., Cinquepalmi F., Astiaso Garcia D. The use of environmental sensitivity indices (ESI) maps for the evaluation of oil spill risk in Mediterranean coastlines and coastal waters. Third International Conference on Sustainable Development and Planning. WIT Transaction on Ecology and the Environmental. WIT Press, 2007. In Press.

[7] Ministero dell'Ambiente e della Tutela del Territorio e del Mare. Parchi d'Italia. Il Sistema delle aree protette. Carsa Edizioni. Ferfefe

[8] Cinelli F. Mappatura delle praterie di Posidonia oceanica e di altre fanerogame marine lungo le coste della Calabria, della Campania e delle piccole isole circostanti. 2003.

[9] Russo G., Carrada G. Caratterizzazione bio-ecologica e bionomica. Parco sommerso di Baia. CoNISMa (Consorzio Nazionale Interuniversitario per le Scienze del Mare) and SBAnace (Sopraintendenza per i Beni Archeologici di Napoli e Caserta).

[10] Gambi M. C., De Lauro M. Ambiente marino costiero e territorio delle isole Flegree. Società Nazionale di Scienze, Lettere e Arti in Napoli. Liguori Editore.

[11] Russo G. Realizzazione del Sistema Informativo Geografico (GIS). Parco Sommerso di Baia. CoNISMa (Consorzio Nazionale Interuniversitario per le Scienze del Mare) and SBAnace (Sopraintendenza per i Beni Archeologici di Napoli e Caserta).

[12] Alongi G., Comarci M., Furnari G., Giaccone G. Prima segnalazione di Caulerpa racemosa (Chlorophyceae, Caulerpales) per le coste italiane. Boll. Acc. Gioenia Sci. Nat., Catania, 26 (342): 49-53

[13] Carrada G., Russo G. Analisi fenologica e della dinamica espansiva di alcuni prati di Caulerpa racemosa. AMP Punta Campanella. Relazione preliminare. CoNISMa (Consorzio Nazionale Interuniversitario per le Scienze del Mare. 